\title{
Discursos em relação a homens e mulheres da pré-história: possíveis implicações no ensino de Biologia
}

\author{
Discourses related to pre-historical men and women: possible \\ implications for biology teaching
}

\author{
Andréa do Carmo Bruel de Oliveira ${ }^{1}$ \\ Bettina Heerdt ${ }^{2}$
}

\section{Resumo}

O objetivo da pesquisa é evidenciar os discursos de acadêmicos/as de licenciatura em ciências biológicas, em relação a homens e mulheres na sociedade pré-histórica. A pesquisa é qualitativa feminista, baseada na interpretação de imagens e narrativas de 29 acadêmicos/as. Para analisar os dados adotamos os pressupostos teóricos das epistemologias feministas nas dimensões crítica e construtiva, discussões da biologia da diferença e a análise de discurso de Foucault, na busca de que algo novo seja produzido. Os discursos apresentados são de homens e mulheres ocupando espaços bem definidos e distintos, o que reforça os discursos científicos do século XVIII da marcação da diferença e o que está presente em materiais didáticos, também são apresentados discursos de homens e mulheres desempenhando funções e ocupando espaços semelhantes e em processo de colaboração, além de discursos que não definiam quem eram homens e mulheres, apenas as atividades exercidas, esses discursos são próximos as teorias feministas. Discursos contraditórios que defendiam a igualdade, mas que demarcavam as diferenças entre homens e mulheres também foram encontrados. $O$ ensino de Biologia pode possibilitar (re)construções, levantar dúvidas para repensar verdades (im)postas que são reafirmadas no ensino e mantém discursos de poder e dominação.

Palavras chave: discursos da evolução humana; questões de gênero no ensino de ciências e biologia; formação docente e gênero.

\section{Abstract}

This study aims to evidence the discourses produced by students in the biological sciences teaching undergraduate course regarding men and women in pre-historical societies. This is a qualitative feminist study, based on the interpretation of images and narratives produced by 29 university students. The theoretical principles of feminist epistemologies in their critical and constructive dimensions, difference biology discussions and discourse analysis were adopted to analyze the data, seeking to produce something novel. Regarding the discourses analyzed, some produced reinforced scientific ideas from the XVIII century that marked the difference, in which men and women occupy well-defined and distinct spaces. Others were closer to the feminist theories and depicted men and women performing similar actions and occupying the same spaces in a collaborative process, while some did not define men and women, only the possible activities developed by people. Contradictory discourses that defended equality, but marked differences were also found. Our results led us to

\footnotetext{
${ }^{1}$ Faculdade Educacional da Lapa - FAEL | andreacbruel@gmail.com

${ }^{2}$ Universidade Estadual de Ponta Grossa | bbheerdt@uepg.br
} 
propose such a biology teaching that enables (re)constructions and is open to doubts that lead people to rethink (im)posed truths that support discourses of power, domination and dichotomies, and also creates the possibility of reflecting on the female and male pluralities.

Keywords: gender and biology teaching; human evolution discourses; teachers' initial education.

\section{Introdução}

A marcação da diferença dos corpos, dos sexos, dos gêneros ocorreu a partir da metade do século XVIII e durante o século XIX, portanto uma construção histórica. Verdades foram produzidas pela ciência, religião, direito, instituições educativas e tornaram-se naturais. Rohden (2001, p.13) descreve "uma inquietação a respeito da obsessão com a definição das diferenças entre homens e mulheres". O discurso da diferença resultou em produção de desigualdades e de inferioridade das mulheres em relação aos homens. Rohden(2001, p. 29) cita obras de médicos em que "o corpo masculino é quase sempre descrito como superior em relação ao feminino. Além disso, insiste-se na ideia de que as características femininas refletiriam a missão passiva que a natureza reservara à mulher, além de uma predestinação à maternidade".

Na metade do século XIX, entre essas discussões científicas da marcação da diferença, Darwin apresenta o processo de seleção natural e sexual para explicar a evolução das espécies, as diferenças estavam demarcadas entre machos e fêmeas de diferentes espécies, os machos apresentados com características de ativos, corajosos, competidores e agressivos, as fêmeas como recatadas, passivas e observadoras, que "geralmente exercem alguma escolha ao aceitar um dos machos vitoriosos" (SCHIEBINGER, 2001, p. 246). A demarcação da diferença nesta teoria também resultou na inferioridade das mulheres, como por exemplo, na descrição de que a "transmissão igual de caracteres permitia que características selecionadas para os machos fossem transmitidas para as fêmeas" (SCHIEBINGER, 2001, p. 258).

A desvalorização feminina elaborada por deterministas biológicos estrutura diferenças naturais, nas quais o macho/homem é colocado em uma posição inerentemente superior a fêmea/mulher subalterna; que apesar de ocupar um status inferior e desvalorizado, se dá por satisfeita por poder usufruir da proteção e da valorização dos prazeres maternos. Há de fato diferenças biológicas, mas, estas recebem peso e significado conforme os valores de uma determinada cultura (ORTNER, 1979). Em outras palavras,

o corpo feminino parece condená-la a mera reprodutora da vida; o homem, em contraste, não tendo funções naturais de criação deve (ou tem a oportunidade de) basear sua criatividade externamente "artificialmente" por meios de símbolos e tecnologia. Assim agindo, ele cria objetos relativamente duradouros, eternos e transcendentes, enquanto a mulher cria seres perecíveis - os seres humanos (ORTNER, 1979, p. 104).

Na década de 1970, período em que as discussões feministas eram notórias, as suposições dos distantes ancestrais da espécie humana foram questionadas por feministas de diversas áreas do conhecimento (arqueologia, paleologia, antropologia, e biologia evolucionária). A hipótese do "homem caçador", que coexistia com o modelo do babuíno dominador, foi questionada e uma nova hipótese surge, a da "mulher coletora" (SCHIEBINGER, 2001). No entanto, ambas as hipóteses mantêm dualismos e reafirmam 
diferença, atribuindo a homens e mulheres papéis distintos, e provavelmente pouco descrevem a evolução humana (HEERDT, 2014).

$O$ discurso da diferença de gênero (homem e mulher) instituiu hierarquias e construiu desigualdades. A partir dos anos 80 reposiciona-se o discurso da diferença entre as próprias mulheres, não temos mais uma única categoria mulher. Ocorre uma reelaboração das proposições anteriores, sob essas nossas perspectivas são enfatizadas as "diferenças de intersecções múltiplas" entre e dentro das mulheres, como raça, etnia, classe, orientação sexual, idade, religião, nacionalidade, entre outros (COSTA, 2002). A história da evolução humana é anacrônica, e representa as mulheres diferentes e inferiores aos homens, e iguais entre si, desempenhando mesmas funções e ocupando os mesmos espaços.

As investigações em educação em ciências, tanto nos âmbitos nacional quanto internacional, que buscam sistematizar as discussões de gênero e Educação Científica são ainda primárias. Como apresentados nos levantamentos realizados nos principais periódicos e eventos da área de Educação em Ciências e Matemática (BATISTA et al. 2011; HEERDT, 2014; SILVA, SANTOS \& HEERDT, 2017; HEERDT et al.2018). O ensino de ciências e biologia, muitas vezes, por intermédio de seus conteúdos e práticas contribuem para a manutenção de desigualdades e demarcações de diferenças. Destacamos a evolução humana como um dos conteúdos científicos ensinados e aprendidos na biologia, o qual é permeado pelas questões de gênero com discursos sexistas e estereótipos machistas (OLIVEIRA, 2019).

Os questionamentos que nos move é: quais são os discursos de acadêmicas/os de biologia em relação a homens e mulheres da pré-história? Quais as possíveis implicações dos discursos presentes em imagens e narrações no ensino de biologia? O objetivo da pesquisa é evidenciar os discursos de acadêmicos/as de licenciatura em Ciências Biológicas, em imagens e narrativas em relação a homens e mulheres na sociedade pré-histórica. A pesquisa é qualitativa feminista, baseada na análise do discurso de imagens e narrativas de 29 acadêmicos/as. Para analisar os dados adotamos os pressupostos teóricos das epistemologias feministas nas dimensões crítica e construtiva, além das discussões da biologia da diferença.

\section{Pressupostos teóricos metodológicos da pesquisa}

Nesta pesquisa buscamos responder aos questionamentos: quais são os discursos de acadêmicas/os futuros de biologia em relação a homens e mulheres da pré-história? Quais as possíveis implicações dos discursos presentes em imagens e narrações no ensino de biologia? Para isso, utilizamos a metodologia qualitativa e feminista que Denzin e Lincoln (2006, p.17) definem genericamente como "uma atividade situada que localiza o observador no mundo". Na perspectiva feminista a pesquisa supõe que o conhecimento é possível ao sujeito corporificado, o/a conhecedor/a é situado/a, assim as pesquisadoras desta pesquisa se caracterizam como mulheres, brancas, feministas, heterossexuais, mães, professoras no ensino de ciências e biologia, portanto, possuem uma relação emocional com o objeto de conhecimento, "conhecedores interagem com os objetos de conhecimento, são afetados e modificados por eles" (LONGINO, 2008, p. 519).

Os sujeitos desta pesquisa são considerados como corporificados e localizados em um dado momento histórico e social, são acadêmicas/os do $4^{\circ}$ ano, vespertino e noturno, têm idade entre 21 e 26 anos, sendo 24 mulheres e 5 homens, cursam Ciências Biológicas licenciatura no Estado do Paraná. A escolha deste grupo se deu pelo fato de já possuírem 
conhecimentos prévios acerca do conteúdo de evolução humana, disciplina que é ofertada no primeiro semestre do $4^{\circ}$ ano do curso. Os sujeitos foram identificados pelas letras BLm (biologia Licenciatura - mulher) e BLh (biologia Licenciatura - homem), acompanhado de um número que foi estabelecido de maneira aleatória, mantendo a identidade dos/as participantes em sigilo. A pesquisa foi submetida para avaliação no Comitê de Ética, sendo aprovada pelo Parecer Consubstanciado de número 2631439.

Foi construída uma unidade didática (UD) que teve objetivo formativo e de produção de um corpus para análise, em que as/os acadêmicas/os tiveram a oportunidade de expressar e refletir as relações de gênero no conteúdo de evolução humana. A UD foi dividida em quatro encontros, apenas a atividade 2 do encontro II, está sendo analisada neste artigo.

Em todos os encontros as/os acadêmicas/os, em sua grande maioria, foram receptivos e colaboraram realizando as atividades individuais ou em dupla, conforme o proposto. Após a conclusão das atividades, por intermédio de uma apresentação, eram conduzidos a refletir acerca sobre do que haviam produzido. Destacamos que em alguns momentos, os acadêmicos apresentavam certa resistência em aceitar as discussões de gênero, muitas vezes apresentando como justificava a inexistência de diferenças nas relações entre homens e mulheres; sendo que situação similar não foi percebida em relação às acadêmicas.

Na segunda atividade do II encontro da UD, os/as acadêmicos/as receberam uma folha com imagens de fósseis de uma sociedade primitiva, a partir dessa imagem representaram por intermédio de um desenho, a suposta sociedade na qual estariam inseridos esses fósseis (adaptado de ABD-EL-KHALICK; BELL, LEDERMAN, 1998). Essas imagens fazem parte das pesquisas realizadas no século XIX, pelo naturalista dinamarquês Peter Lund que descobriu ossos humanos numa caverna de Lagoa Santa (MG) e iniciou uma série de escavações, tornando-se uma das mais duradouras pesquisas arqueológicas no país. Nesse local foi encontrado o fóssil de Luzia e seu povo, que habitaram a região de Lagoa Santa, há cerca de 10 mil anos, faziam parte um grupo denominado paleoamericanos. As figuras 01 e 02 foram as apresentadas para as/os acadêmicas/os.
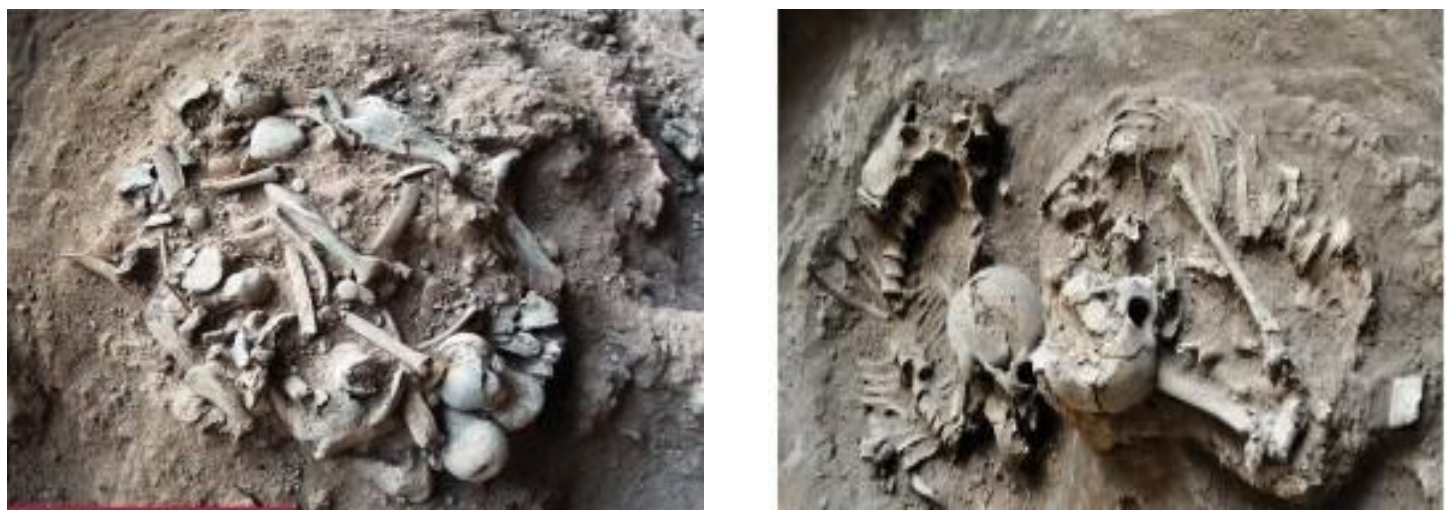

Figuras 1 e 2 - Povos da Lagoa Santa. Fonte: Reprodução do site:

http://revistapesquisa.fapesp.br/2016/09/22/os-povos-de-lagoa-santa/

A partir da análise das figuras foi proposto as/aos acadêmicas/os desenhar a possível sociedade na qual estes fósseis habitavam, levando em conta quem seriam esses indivíduos, que atividades provavelmente exerciam e que tipos de relações existiam entre eles/elas. Concluída a etapa da elaboração dos desenhos as/os acadêmicas/os responderem as seguintes questões: Que tipo de relação há entre homens e mulheres? Ocorreram 
mudanças no transcorrer da Evolução Humana, entre homens e mulheres? Nesse momento, ao realizarem a atividade proposta, as/os acadêmicas já tinham refletido algumas questões de gênero tanto na sociedade quanto na ciência.

Para dar visibilidade aos discursos trazidos nas imagens e narrativas das/os acadêmicas/os utilizamos as epistemologias feministas (LONGINO, 2008; KELLER, 2006, SCHIEBINGER, 2001) nas dimensões críticas e construtivas, as dimensões críticas incluem a representação de formas de preconceito masculino no centro das análises filosóficas de temas como objetividade, razão, conhecimento e racionalidade. As dimensões construtivas requerem a criação de uma área para projetos especificamente feministas de análise, identificação ou defesa das diretrizes epistêmicas de investigação feminista (LONGINO, 2008).

\section{Epistemologias feministas e as relações de gênero na evolução humana}

A Epistemologia, para Longino (2008, p. 505) vem a ser "um campo de pesquisa extremamente amplo, que investiga o significado das afirmações e atribuições do conhecimento, as condições e possibilidades do conhecimento, a natureza da verdade e da justificação". Já o feminismo "é um conjunto de posições e investigações [...] sociopolíticas comuns centralizadas na abolição da desigualdade de sexo e gênero. Assim sendo, para a autora, as epistemologias feministas passam a ser primordiais, na busca de investigar as relações de gênero nas diversas atividades epistêmicas, considerando que existem preconceitos de gênero impregnado nas diversas áreas do conhecimento humano.

A crítica feminista da ciência foca em uma esfera especialmente fértil, as categorias do pensamento ocidental que precisam ser revisadas. As críticas iniciaram a partir de interrogações no âmbito político, voltadas primeiramente ao que diz a respeito à discriminação às mulheres na base social da ciência, do preconceito androcêntrico nas ciências sociais e na biologia, resultando em volumosa interpelação às alegações do pensamento ocidental moderno. Dessa forma, as críticas tacitamente desafiam as estruturações teóricas em que as perguntas iniciais foram elaboradas, e segundo as quais poderiam ser questionadas (HARDING, 1993). As críticas ao conhecimento científico moderno hegemônico, que embora sejam resistentes não são eternas. O que faz com que a crítica feminista, desafie o "ethos" masculino da ciência (BANDEIRA, 2008).

$O$ que se denota é que a crítica feminista vem apontar que o androcentrismo tem ido muito além da simples isenção das mulheres do mundo da ciência, mas se apresenta de maneira decisória não só na composição da cultura da ciência, como também no conteúdo dos conhecimentos produzidos nas instituições. O poder da ciência ocidental proclama um conhecimento objetivo e universal que transcende as culturas, em relação a gênero, raça, classe social, entre outros. A ciência não pode ser tida como neutra, pois as desigualdades são incorporadas nas instituições e nos conhecimentos (SCHIEBINGER, 2001).

Para a crítica feminista, "qualquer forma de ciência que seja considerada ou proposta como universal deve ser duramente criticada, uma vez que todas as categorias pretensamente universais acabam por fixar parâmetros permanentes, inclusive de poder" (BANDEIRA, 2008, p.213). As feministas partem do pressuposto que os procedimentos teóricos se constituem como método de conhecimento em um determinado contexto social momentâneo. Métodos e padrões universais podem passar a constituir o centro e/ou redutos de um modo de dominação, ao qual se estabelece uma crítica direta das feministas. Mesmo em laboratório não se encontra um sujeito único e universal. Em vista disto, 
"desconstruir e criticar as totalidades universais que formam, entre outros, o arsenal de concepções teóricas predominantes passa a ser o alvo com o qual, fundamentalmente, lida a crítica feminista" (BANDEIRA, 2008, p.214).

Consequentemente se justificaria a busca pela desconstrução das metáforas de gênero presentes no conhecimento científico, expostas por cientistas feministas, as quais têm influenciado na constituição da pauta epistemológica feminista. Tendo em vista que, uma das primeiras preocupações das feministas foi a representação de que machos de uma espécie são dominantes e detentores de atributos cuja importância social tem mais peso que o das fêmeas (LONGINO, 2008). No mesmo sentido, Keller (2006), apresenta metáforas da biologia celular, da biologia evolutiva, na ecologia e da genética, como por exemplo, as descrições relativas à dinâmica molecular da fertilização em que o óvulo era dito como pacífico o que na atualidade não é mais visto dessa maneira. Na Biologia evolutiva as metáforas se apresentam quase sempre nas descrições das relações entre homens e mulheres, como argumenta Schiebinger (2001, p.258) "trazer para o lar os animais selvagens abatidos tornou-se o "comportamento do senhor" da espécie humana. O homem, ativa e agressivamente, impulsionou para frente à evolução; [...] as mulheres pré-históricas foram transformadas em criadas invisíveis para os homens".

As mudanças culturais introduzidas pela categoria de gênero com ocorrência, não de modo específico na teoria social, mas deslocadas ao domínio das Ciências Biológicas, por exemplo, muitos estudiosos não imaginavam que o conceito de gênero seria um fator primordial de desenvolvimento social e científico, desprezado pela História da Ciência, cuja importância se evidencia também a partir da crítica feminista (Keller, 2006). Ao se pensar/produzir uma ciência múltipla, polifônica, inclusiva e equitativa do ponto de vista de gênero, o olhar também foi para outros marcadores sociais, tais como etnia, raça e situação econômica (HARAWAY, 1995; KELLER, 2006).

A Ciência, dependendo do momento histórico em que é produzida, possui crenças e preconceitos ocultos, que muitas vezes, não são verbalizados. Na arqueologia juntamente com outras ciências, como a paleontologia e especialidades envolvidas na história da evolução humana, produzidas na sua maioria apenas por homens, sustentam uma versão masculina da evolução, quase sempre isenta de mulheres (ADOVASIO, SOFFER, PAGER,2009).

Na biologia, o gênero vai além da feminilidade e masculinidade, atribuídos aos animais e plantas anônimas, pode tornar-se codificador em práticas, instituições e nas preferências das pesquisas científicas (SCHIEBINGER, 2001). Na taxionomia há exemplos consagrados que evidenciam como o gênero pode tornar-se um organizador silencioso de teorias e práticas científicas, designando preferências e estabelecendo conclusões. O famoso taxonomista Linnaeus em suas classificações priorizava as partes masculinas atribuindo prestígio do organismo no reino vegetal. A subordinação da mulher ao homem, estrutura social específica, era de certa maneira naturalizada por Linnaeus, a partir do momento que fez dessa submissão o princípio norteador de sua taxionomia botânica, na qual as partes femininas da planta estão subordinadas as partes masculinas, reforçando e naturalizando práticas sociais da época, nas quais revelavam a personalidade conservadora desse cientista. Ainda que de maneira inconsciente, essas convenções de gênero, que são imputadas a natureza, acabam por reforçar "a privação das mulheres da cultura pública tanto da ciência como da sociedade civil enquanto teóricos sociais tentavam construir uma sociedade justa baseada na lei natural" (SCHIEBINGER, 2001, p. 285/6). 
A evolução humana é outro exemplo, das relações de gênero e ciência, a maioria de nós cresceu com uma imagem da evolução humana como sendo a "evolução do homem", a caça é apontada como uma evidencia de que o homem foi responsável pela evolução da humanidade, essas histórias são propagadas em ilustrações de revistas e livros, em dioramas de museus que retratam cabanas construídas com ossos de mamutes, como o Museu de História Natural de Nova York e o de Paleontologia de Kiev na Ucrânia. Nestes cenários a participação das mulheres é sem significado, são retratadas como consumidoras dependentes. As discussões atuais apresentam as dificuldades, tanto de homens, quanto de mulheres, por conta dos riscos, de caçar grandes animais, a maior probabilidade era de caça de animais menores (ADOVASIO, SOFFER, PAGER, 2009).

Nas descrições das pinturas rupestres de Grotte de Rouffignac, a invisibilidade da mulher continua, num dos sítios arqueológicos mais ricos da Europa e do mundo, retratam pelo menos 250 estampas e gravuras de animais pré-históricos e humanos. As descrições trazem relatos de iniciações, em que jovens são levados a gruta por homens mais velhos e o ancião responsável por direcionar todo o ritual, os jovens serão iniciados a vida de caçadores. Os registros apresentados acerca dessas gravuras e de outras pinturas rupestres não apresentam as mulheres em nenhum momento, e nem tão pouco meninas em ritual de iniciação. Essas representações artísticas, por décadas, foram vistas como domínio masculino, assim como a caça, para a aquisição de carne. A suposição era que neste período as mulheres nunca sequer pisaram em tais lugares, e que se caso ali estiveram, não se envolveram de modo ativo na criação (ADOVASIO, SOFFER, PAGER, 2009).

Apesar das atribuições da mulher na evolução terem passado por uma sucessão de permutações, paradoxalmente, os resultados demonstram que as mudanças em relação a visibilidade da mulher foram poucas. Na década de 90, os antropólogos conseguem uma ampla divulgação por meio dos livros, especiais de televisão e exibições em museus, nos quais a mulher não é considerada como partícipe no processo evolutivo humano, e quando representada, aparece como uma mera serva do homem pré-histórico. Esforço consciente ou não por manter as mulheres "em seu lugar, essas atitudes generalizadas impõem um 'teto de vidro' às nossas ancestrais, muito parecido com o 'teto de vidro' que limita a mobilidade ocupacional ascendente das mulheres contemporâneas dentro e fora das disciplinas acadêmicas" (ZIHLMAN, 1997, p.5, tradução nossa).

Anunciar as atribuições de homens e mulheres na história da evolução humana é algo passível de contestação, já que quanto mais distante são os registros encontrados, maior é a dificuldade. No entanto, nas descrições científicas ocorre a invisibilidade das tarefas desempenhadas pelas mulheres e as tarefas desenvolvidas pelos homens são incrementadas, com ricos detalhes (ADOVASIO, SOFFER, PAGER, 2009).

O discurso da diferença parece ser necessário para demonstrar e comprovar como teríamos marcos naturais intransponíveis, como o caso das histórias da vida humana préhistórica, que assegura uma distinção radical entre os gêneros. "A diferença percebida entre homens e mulheres faz parte do conjunto de temas centrais a partir do qual cada sociedade se pensa a si mesma e propõe suas formas de organização social" (ROHDEN, 2001, p.13). A biologia em seus diversos conteúdos, o conceito da diferença se fundamentou em relações de dominação e exclusão, o ser diferente significa ser menos.

Ao levarmos em consideração, a diferença pode também ser pensada "como referência à pluralidade feminina ou multiplicidade de posicionalidades relacionais, e as interseccionalidades constituem-se nos grandes desafios teórico no trabalho de diluição das 
dicotomias e dos seus poderes". A diferença como modo de desnaturalizar argumentos essencialistas e universais de homens e mulheres atuais (FURLIN, TAMANINI, 2017, p. 328)e da pré-história. Os discursos da ciência moderna performatizam estruturas hierárquicas, produzem a mulher como o outro sujeito masculino, esse discurso está presente nas reconstruções históricas dos modos de vida em sociedade dos homens e mulheres da préhistória em que é propagada uma única identidade.

\section{Epistemologias feministas: críticas e construções no ensino de evolução humana}

No ensino de Ciências/Biologia podemos pensar a dimensão crítica ao questionarmos os conhecimentos propostos no ensino e como são ensinados, muitas vezes de forma acrítica, neutra. Na dimensão construtiva propor projetos de ensino que desestabilizem certezas, em especial aquelas que envolvem gênero e suas interseccionalidades, a pedagogia feminista é um meio fértil para isso.

A pedagogia feminista para Sardenberg (2011, p. 19) é um "conjunto de princípios e práticas que objetivam conscientizar indivíduos, tanto homens quanto mulheres, da ordem patriarcal vigente em nossa sociedade, dando-Ihes instrumentos para superá-la", questionálas. Trazendo na sua trajetória distintas vertentes, que se igualam por contribuírem para a modificação das relações entre o gênero na sociedade moderna, por meio de modelos e práticas político-pedagógicas. O objetivo desta pedagogia é libertar diferentes homens e mulheres das amarras das ideologias e hierarquias de gênero, por meio das reflexões da ordem patriarcal (SARDENBERG, 2011).

Os discursos da pedagogia feminista, segundo Luke (1996), têm estado na vanguarda da reconceptualização, praticando diferentes formas de saber, ao mesmo tempo em que despreza muito do que é dado como certo por parte da cultura universitária e ethos, recusa hierarquias de poder e autoridade competitivas, rejeita a equação comum do/a professor/a como conhecedor/a e aluno/a como o que desconhece e que é teoricamente ingênuo/a. Pedagogicamente, ensinar se concentra nas diferenças. Faz da produção do conhecimento um esforço de classe colaborativa, em que o/a pedagogo/a feminista tem um corpo específico para oferecer conhecimentos e experiências. Presume-se que tal pedagogia procuraria teoricamente combinar a dinâmica sedutora do conhecimento, ao modelo engendrado de professor/a e aluno/a, com uma ética fundamentada em resistência a todas as formas de poder abusivo e injustiças sociais (LUKE, 1996, tradução nossa).

Ao relacionarmos o ensino de evolução humana as teorias feministas, passamos a pensar e duvidar das convenções de gênero e ciência, muitas vezes, impostas no ensino de biologia. Propomos pensar na linguagem, na naturalização dos processos, nos padrões dualistas e binários, na visibilidade das mulheres no processo evolutivo e na colaboração para o processo de evolução humana.

A pedagogia feminista quando propõem romper com as resistências trazidas nos discursos, leva a compreender a importância de que questões de gênero no ensino de evolução humana sejam problematizadas junto aos/as aluno/as, oportunizando que se façam as críticas e questionamentos ao que se traz como "verdade" nas descrições do processo evolutivo. Repensar os padrões androcêntricos da linguagem no ensino de evolução humana é primordial e indispensável, discursos em que o "homem é o senhor da espécie", ou ainda "a evolução do homem", são recorrentemente assim apresentados, e em muitos casos não causam estranhamento. Essa linguagem pode vir a certificar cientificidade 
às justificativas de que a mulher é inferior ao homem, ou ainda justificar seu papel de subordinação.

A naturalização das distinções trazidas nos episódios que descrevem o processo de evolução humana, especialmente aqueles que envolvem as práticas cotidianas de homens e mulheres da pré-história, devem passar a ser questionadas, um elemento significativo é utilizar das críticas feministas da ciência para compreender como a ciência é construída, as metodologias de obtenção de dados e análise de fósseis, pois, muitas vezes, ensinamos os conceitos finais produzidos pela ciência, impossibilitando as/os alunas/os o questionamento e a dúvida.

A colaboração no processo de evolução humana e as diferentes atividades desempenhadas por homens e mulheres para a sobrevivência da espécie devem ser debatidas, não como verdades absolutas, mas como possíveis estratégias de sobrevivência. Tanto as mulheres participavam da confecção de instrumentos de caça quanto caçavam, e que os homens igualmente se empenhavam aos trabalhos manuais, como a costura e confecção de artefatos de palha, como por exemplo, os cestos (ADOVASIO, SOFFER, PAGER, 2009). Poderíamos questionar: seria está à provável história? Ou mais coerente? São incertezas que as/os alunos devem pensar e refletir.

Para se compreender como se dá as relações de gênero no ensino de evolução humana, não se deve fundamentar as propostas educacionais inclinadas somente na transmissão de conteúdos ou práticas"há que se deslanchar um processo transformativo, no sentido de quebrar resistências" (SARDENBERG, 2011, p. 21), tanto em relação aciência como verdade e neutra, quanto em relação as questões de gênero que permeiam os discursos científicos.

As práticas educativas fabricam sujeitos, produzem identidades étnicas, de gênero, de classe. Essas identidades estão sendo produzidas por meio de relações desiguais, o que mantém a sociedade dividida, e isso ocorre cotidianamente, com a participação ou omissão das/os professoras/es. A prática escolar é historicamente contingente e é uma prática política, isto é, que se transforma e pode ser subvertida, se as/os professoras/es não se sentirem conformados com essas divisões sociais, então, certamente, encontramos justificativas não apenas para observar, mas, especialmente, para tentar interferir na continuidade dessas desigualdades, desses jogos de poderes (LOURO, 2014).

Para Sardenberg (2011, p. 22) "podemos instrumentar pessoas para trabalhar com a análise de gênero, mas esse "novo olhar" necessário não chega de forma automática. Não é algo passível de ser "ensinado", mas o resultado de um processo que se desenvolve aos poucos e em ritmos diferentes", e precisamos pensar e refletir essas questões no ensino de biologia.

\section{Tratamento das informações: a análise do discurso}

A perspectiva da análise do discurso adotada tem por pressuposto que o discurso é uma prática produtiva de verdades, saberes, sentidos, subjetividades. A análise do discurso, na perspectiva foucaultiana, daria conta "das relações históricas, de práticas muito concretas, que estão "vivas" nos discursos "(FISCHER, 2001, p.198 e 199). O discurso não é uma mera expressão, textos, instituições, falar e ver, constituem-se em práticas sociais que "estão presas, amarradas as relações de poder" (FISCHER, 2001, p. 200). 
A teoria feminista contemporânea, por considerar que a análise do discurso coloca-se em prol da busca de superação de questões que dizem respeito às circunstâncias de dominação, de lutas hegemônicas e de poder; têm buscado a análise do discurso como ferramenta metodológica no desenvolvimento de suas pesquisas vislumbrando as possibilidades de reflexões no que tange a tradição científica das metodologias e conceitos consagrados, bem como as possíveis buscas das ideologias inclusas nos discursos (GABRIELLI, 2007).

O corpus de análise se constitui de imagens e textos produzidos por acadêmicas/os do do quarto ano, vespertino e noturno, do curso de Ciências Biológicas de uma universidade pública da cidade de Ponta Grossa, Paraná, Brasil, obtida mediante a realização de uma intervenção, na qual se construiu uma unidade didática, dividida em quatro encontros, na disciplina de Laboratório de Ensino de Ciências e Biologia, realizada durante o primeiro semestre de 2018.

A imagem é um "meio de comunicação e de representação de mundos, têm um lugar central na contemporaneidade" (SCHWENGBER, 2014, p. 267). Propomos compreender a relação da imagem com o texto, no sentido de acrescentar a pesquisa dados discursivos. Organizamos unidades provisórias, não para buscar a origem de um determinado discurso, nem a intenção de quem produz certos discursos, mas de analisar o porquê aquilo é dito, daquela forma em determinado tempo e contexto, interrogando as condições de existência do discurso.

Para a análise os elementos sociais das imagens foram observados diferentes aspectos, tais como: poses, gestos, vestimentas, acessórios, o enquadramento, o que circula a imagem, como se dirige e o que ensina (SCHWENGBER, 2014, p. 270). As seguintes questões foram levantadas para a análise das imagens: Como se posicionam homens e mulheres da pré-história? Qual o discurso? Qual o grupo de enunciados que o compõem? Ainda conforme Schwengber (2014, p. 271), olhamos "a insistência, a repetição e a regularidade de certos enunciados e também o que escapa, o que rompe, o que desarranja essa regularidade".

Os discursos foram analisados dentro de um espaço discursivo, o campo de saber científico em relação ao ensino da evolução humana, segundo o qual se "sabe" o que pode e o que deve ser dito, dentro de determinado campo e de acordo com certa posição que se ocupa nesse campo, no caso aqui acadêmicas/os de Biologia e futuros docentes, os falantes se reconheceriam, porque as significações parecem óbvias e naturais. Para Foucault a pratica discursiva não é "mera expressão de ideias, pensamentos, formulações de frases", mas afirmações de verdades de um tempo, falar segundo determinadas regras, e expor as relações que se dão dentro de um discurso (FISCHER, 2001, p. 204). Quando a/o professor se apropria do discurso científico de homem provedor e mulher coletora e consumidora, fala e faz um discurso segundo algumas de suas regras que fixaram enunciados da figura da mulher e do homem na pré-história. A ciência e a escola são veículo de divulgação e circulação dos discursos considerados "verdadeiros" em nossa sociedade. 


\section{Os discursos das/os acadêmicas/os em relação aos homens e mulheres da pré-história}

Os discursos das/os acadêmicas/os são históricos, repetem em muitos momentos, práticas concretas construídas no início do século XVIII, da marcação da diferença e estão vivas nos discursos. As relações entre homens e mulheres na pré-história são representadas em que papéis distintos, de forma bem definida e envoltos em relação de poder (figura 03 e 04).
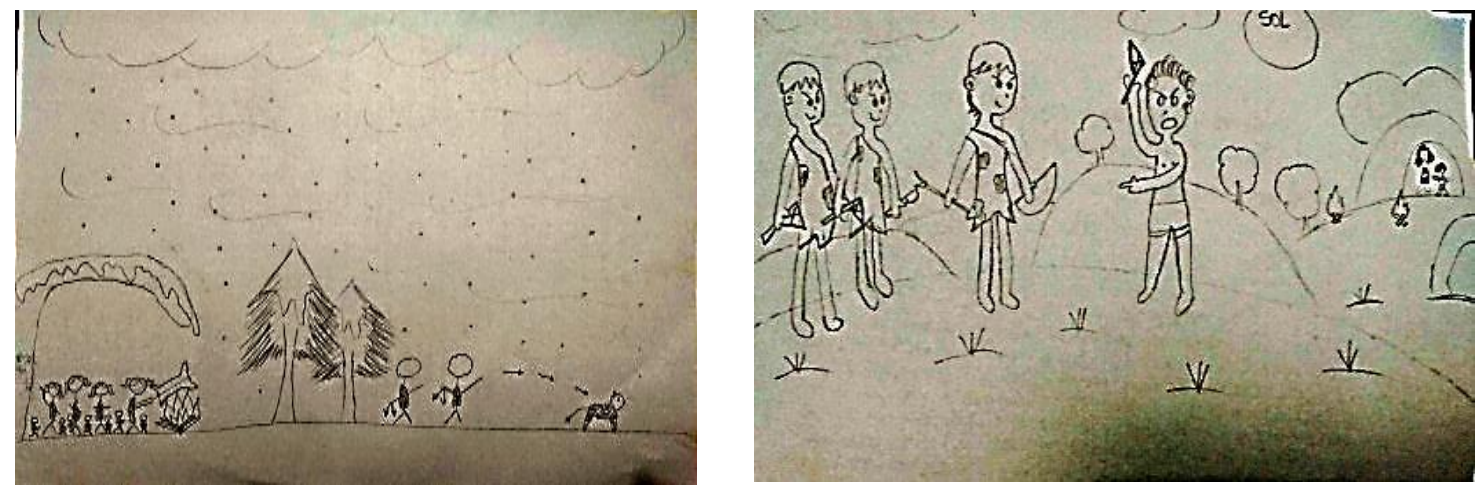

Figura 3 e 4 - Imagem de homens e mulheres na pré-história. Fonte: acadêmicasBLm15 e BLm12

A ciência produziu discursos em que homens e mulheres são diferenciados biologicamente, e essa diferença permitiu que ocupassem espaços distintos na sociedade, os discursos da evolução humana naturalizam papeis de homens e mulheres na sociedade pré-histórica e atual. As imagens exemplificam a de outros cinco acadêmicos/acadêmicas (BLm 10, BIm 02, BLm05,BLh13, BLh06) que carregam enunciados simbólicos em que homens e mulheres são apresentadas em planos distintos (mulheres ambiente interno e homens ambiente externo), exercendo atividades distintas, os acessórios dos homens são armas para a caça, mulheres sem acessórios e rodeadas por crianças, o ambiente que os circunda é o natural.

Além da imagem o texto reafirma o discurso "Os homens saiam para a caça, buscar alimento e água. As mulheres ficavam em um abrigo (protegida da neve, predadores, etc.), cuidando das crianças, protegendo seu abrigo". As acadêmicas BLm12 e BLm10, apresentam que: "No desenho quis representar uma luta por território entre espécies diferentes, onde o homem se prepara para proteger sua família que se encontra com filhos no interior do local que usavam como moradia" e "[...] As mulheres no desenho estão atrás cuidando do alimento e da prole, e o homem à frente para atacar e defender com instrumentos de ataque e de caça". Os discursos das acadêmicas relatam uma relação de poder e cuidado por parte dos homens, sendo o homem o único responsável por prover o alimento e proteger a família. Já a mulher tem como função cuidar dos filhos e do alimento trazido por estes homens, permanecendo apenas no local que usam de moradia e sendo protegidas pelos homens. No discurso dessas acadêmicas, o que se pode analisar é que existe um único modo de pensar o homem e a mulher na pré-história, um homem forte e habilidoso e uma mulher frágil, que precisa ser cuidada, mas que não esquece seu zelo maternal, repetem um discurso de verdade construída.

A reprodução acrítica do discurso da dominação masculina e o autoritarismo apresentados em muitos episódios da evolução humana, naturalizam modelos de homens e 
mulheres, e contribuem para a construção e a manutenção de desigualdades sociais impostas.

Na figura 05 as mulheres estão próximas ao fogo preparando o alimento, enquanto o homem está ao fundo da imagem como o provedor do alimento, segurando uma lança de caça.

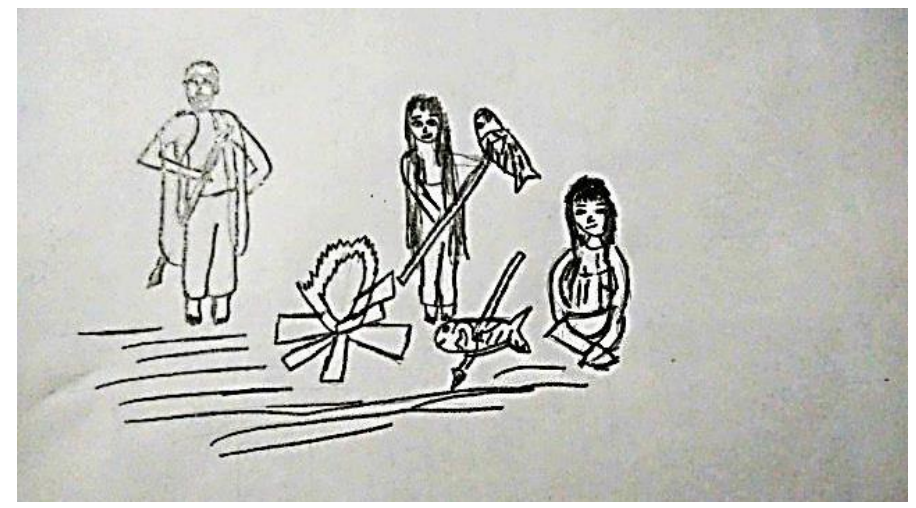

Figura 5 - Imagem de homens e mulheres na pré-história. Fonte: acadêmica BLm5

A acadêmica BLm5 diferencia e dicotomiza papéis, no entanto em sua descrição retrata que "Tanto homens como mulheres trabalhavam, mulheres faziam trabalhos pesados também...", a diferença entre imagem e descrição retrata a facilidade de discursos contraditórios, pois as questões de gênero são naturalizadas em nossa sociedade e por vezes, não percebemos as relações desigualitárias que são socialmente construídas. Imagens semelhantes as apresentadas pelas acadêmicas BIm5, BLm15,BLm12estão presentes em materiais didáticos, como os livros didáticos que reforçam esses discursos.

Foram apresentadas onze imagens, entre as/os acadêmicas/os, que representam um discurso de igualdade entre os homens da pré-história em que todos realizavam atividades colaborando entre si, ou que não definiam entre os indivíduos quem era homem e quem era mulher (Figura 6 e 7 ).
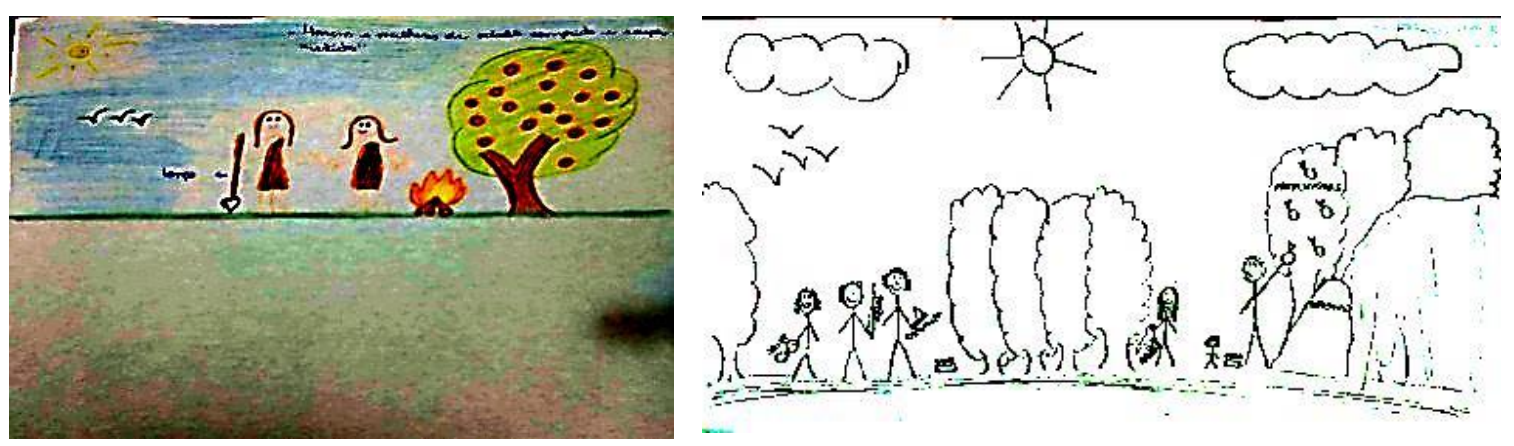

Figura 6 e 7 - Imagens de homens e mulheres na pré-história. Fonte: acadêmica BLm27 e BLm19

As situações de igualdade foram representadas nas relações de trabalho, pela busca do alimento para a sobrevivência, pela relação parental e cuidado com as/os filhas/os. Em uma das narrativas a acadêmica questiona que não sabe quando foi que inventaram que o homem é o responsável pela sociedade, o que vem corroborar com as críticas feministas, em relação à visão androcêntrica da ciência. A acadêmica BLm19 narra que: "Não especifiquei nos desenhos as funções de homens e mulheres. Também não defini quais são homens ou mulheres. Mas acredito que as funções eram de equidade, um não é superior ao outro". No relato das relações entre homens e mulheres a acadêmica busca demonstrar 
que não há superioridade entre estes sujeitos na sociedade pré-histórica. Assim como não define as funções que cada um desempenhava, já que estas denominações podem ser compreendidas como convenções sociais e culturais impostas a homens e mulheres.

As imagens exemplificam a de outros nove acadêmicos/acadêmicas que carregam enunciados simbólicos em que homens e mulheres são apresentadas em um mesmo plano, em condições de igualdade, exercendo as mesmas atividades. A questão que podemos colocar é: será esse discurso excludente? Esse discurso inclui a mulher, mas também exclui possibilidades distintas de ser homem e mulher, quando os nomeia como todos iguais, descartam as pluralidades? São questões que podem ser discutidas no ensino.

Na figura 8 a acadêmica não identificou se eram homens ou mulheres, justifica "não identifiquei sexo no desenho, pois não vi na imagem" (BLm22), pelo estudo de fósseis de maneira preliminar, como foi o caso da atividade, não se tem como definir, o mais coerente seria não definir os sexos e discutir a diversidade de possíveis relações que poderia ocorrer entre eles(as).

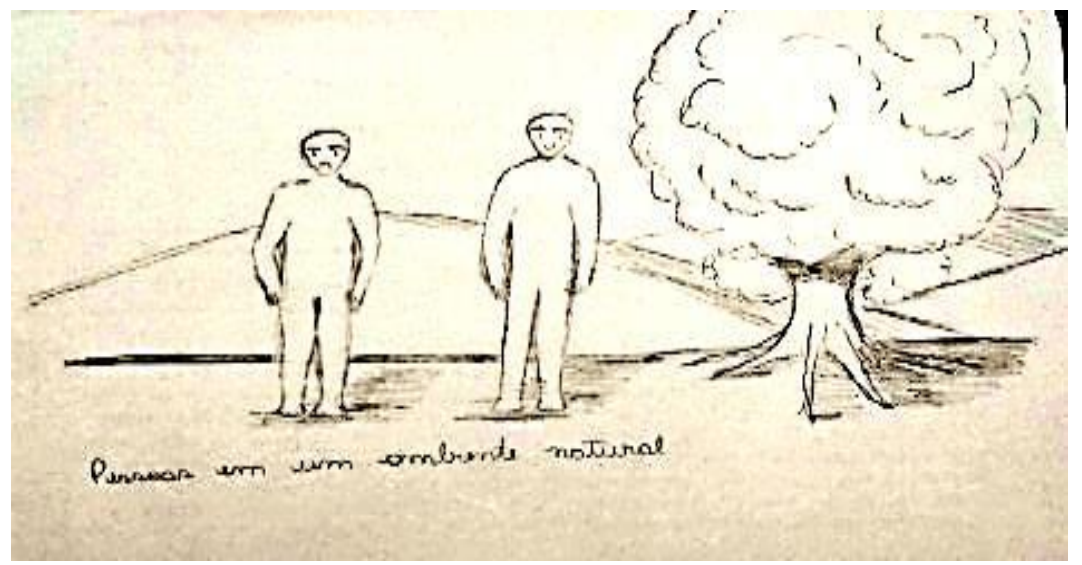

Figura 8 - Imagem de individuos na pré-história. Fonte: acadêmica BLm22

A imagem 8 é apresentada por uma única acadêmica, os indivíduos são apresentados num mesmo plano, em um ambiente natural, não exercem nenhuma atividade. O interessante é que traz um discurso de possíveis pluralidades o que corrobora com discursos da diversidade de relações, e não em discursos pré-definidos.

A figura 9 o acadêmico apresenta conceitos equivocados e em alguns momentos seu discurso é contraditório, de igualdade, mas demarca diferenças.

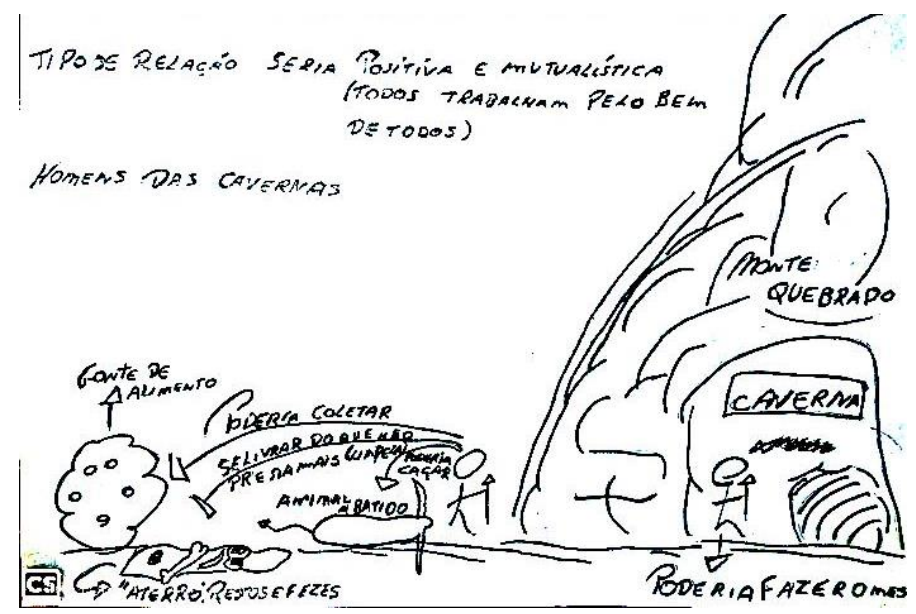

Figura 9 - Imagem de individuos na pré-história. Fonte: acadêmico BLh 07 
No desenho do acadêmico Bh07 seu discurso é contraditório, quando descreve que a relação é positiva, destaca "todos trabalham pelo bem de todos", na biologia isso significa que ambos se beneficiam a relação mutualística, no entanto, é um termo utilizado para populações distintas, o que não é o caso aqui, estamos falando de um mesmo grupo. Na imagem também descreve "Homens das Cavernas" esse discurso invisibiliza as mulheres, é uma linguagem androcêntrica, adotada pela ciência e reproduzida no discurso do ensino de ciências. Na descrição da imagem que o acadêmico diz que não há como identificar quem são os homens e as mulheres, pois são apenas fósseis, mas logo no início da descrição traz que "a relação entre eles era reprodutiva".

As relações de poder que impulsionaram a produção de alguns discursos mostram que esses se articulam com os discursos científicos do século XVIII e que persistem no discurso de futuros docentes até os dias atuais, um discurso da diferença entre homens e mulheres em que as mulheres são invisibilizadas, desvalorizadas e as relações caçador, valente e a mulher consumidora, cuidadora são naturalizadas, discurso que contribui para marcos naturais intransponíveis.

Discursos próximos as teorias feministas da ciência também foram apresentadas por algumas/s acadêmicas/os, esses entram em conflito com o discurso da diferença entre homens e mulheres. Os discursos de igualdade de papéis descrevem não haver diferenças na convivência social entre os indivíduos da pré-história, que todos podem desempenhar a mesma função, seja na busca do alimento ou na preparação e nos cuidados com as/os filhas/os. Para Adovasio, Soffer e Page (2009), é possível que se as relações equânimes não estivessem presentes na sociedade pré-histórica, e se não houvesse colaboração entre ambos no processo evolutivo, é bem provável que a espécie humana não tivesse chegado até onde chegou, mas devemos lembrar que esse também é um discurso produzido.

Na escola, em relação aos discursos da evolução humana a problematização pode ser um caminho, colocar as verdades construídas historicamente em discussão, levantar outras possíveis verdades e discutir o porquê naquele momento de essas era verdade aceita e autorizada. A transposição pedagógica dos conhecimentos científicos para os escolares não é automática, os discursos tidos como verdade e que carregam sexismos, dualismos e naturalizações podem ser reproduzidos, mas também podem ser questionados.

A pedagogia feminista pode ser um meio de superar e enfrentar essas questões na escola, por meio de um conjunto de práticas, estratégias, procedimentos e disposições, que rompam com as relações hierárquicas presentes nas salas de aula tradicionais, princípios pelos quais se objetiva conscientizar mulheres e homens, das normas patriarcais que vigoram nas sociedades, permitindo superar estas normas, de modo que possam construir uma sociedade com equidade entre os sexos (SARDENBERG, 2006, LOURO, 2014) e nessa prática pensar numa ciência mais humana.

Desse modo, é relevante que no ensino de evolução humana se estabeleçam discussões e práticas pedagógicas que busquem desconstruir os discursos de desigualdade encontrados nos materiais didáticos, transpondo esses conhecimentos para as relações de desigualdade existente na sociedade. 


\section{Considerações finais}

O objetivo desta pesquisa foi a de evidenciar os discursos, de acadêmicos/as de licenciatura em Ciências Biológicas, a respeito de imagens e narrativas em relação a homens e mulheres na sociedade pré-história. A pesquisa é qualitativa feminista, baseada na análise do discurso de retratos e narrativas de 29 acadêmicos/as. Para analisar os dados adotamos os pressupostos teóricos das epistemologias feministas nas dimensões crítica e construtiva, além das discussões da biologia da diferença.

Nas análises dos discursos as percepções das relações na pré-história são a de mulheres consumidoras e/ou cuidadoras e os homens produtores e/ou protetores, por vezes a relação é representada como equânime, apesar dessa percepção acabam em alguns discursos naturalizando as relações desiguais entre homens e mulheres. Constata-se no discurso de um acadêmico a resistência em admitir que as discussões das questões de gênero no conteúdo de Evolução Humana se fazem necessária, até porque os referenciais que nos deram suporte para essas análises, trazem entre estudos, a importância de se desconstruir esses alicerces sexistas que certificam e reproduzem o domínio masculino em várias situações.

Temos consciência, que não é apenas com esse poucos momentos de intervenções que os discursos androcêntricos e dicotômicos serão desconstruídos, mas de forma cautelosa, portanto chamamos a atenção para a importância de que mais momentos como esses sejam levados as Universidades, as escolas e aos cursos de formação de professores/as, para que os envolvidos com a formação dos sujeitos inseridos nesses espaços possam perceber a necessidade de trazer nas suas práticas pedagógicas, um novo olhar no que tange as questões de gênero no conteúdo de evolução humana. Até porque se faz necessário anunciar que tipo de conhecimentos os/as futuros/as docentes de Biologia devem apresentar para um ensino de evolução humana reflexivo, no qual se questione e discuta o que é apresentado como verdade nos discursos científicos trazidos nos livros didáticos.

Trazer para as salas de aula reflexões das relações entre homens e mulheres na préhistória, possivelmente levará a uma desconstrução do que é apresentado como conhecimento verdadeiro, inquestionável, o que seria de suma importância, já que muitas dessas relações de poder - como as que foram relatadas por muitas/os das/os participantes - se encontram em nossas escolas e principalmente em nossa sociedade, que dê certa forma ainda persistem em manter um discurso de poder e dominação entre homens e mulheres.

O ensino da biologia deve ser pensado pelos seus professores como um ensino de saberes complexos, heterogêneos, provenientes de fontes diversas, mas que permite reflexões contínuas, o que pode favorecer para que o ensino seja crítico e reflexivo a relação ao que é apresentado como verdade nos diversos discursos científicos. 


\section{Referências}

ABD-EL-KHALICK, Fouad.; BELL, R. L.; LEDERMAN, Norman. G. The nature of science and instructional practice: Making the unnatural natural. Science Education, 82, p. 417-436, 1998. https://doi.org/10.1002/(SICI)1098-237X(199807)82:4<417::AID-SCE1>3.0.CO;2-E

ADOVASIO, James. M.; SOFFER, Olga., PAGE, Jake. O Sexo invisível. Trad. Hermano de Freitas. Rio de Janeiro: Record, 2009.

BANDEIRA, Lourdes. A contribuição da crítica feminista à ciência. Estudos Feministas, Florianópolis, v. 16, n. 1, p.207-230, 2008.

BATISTA, I. de L, et al. Gênero Feminino e Formação de Professores na Pesquisa em Educação Científica e Matemática no Brasil. In: Anais do Encontro Nacional de Pesquisa em Educação Em Ciências, 8.,p.4-5, 2011, Campinas. Atas. Campinas: UNICAMP.

COSTA, Claudia de Lima. O sujeito no feminismo: revisitando os debates. Cadernos Pagu, n. 19, p.59-90, 2002.

DENZIN, Norman, K. O planejamento da pesquisa qualitativa: teorias e abordagens. Trad. Sandra Regina Netz. p. 15- 41. Porto Alegre: Artmed, 2006.

FISCHER, Rosa Maria Bueno. Foucault e a análise do discurso em educação. Cadernos de. Pesquisa. n. 114, p.197-223, 2001. Disponível em https://www.scielo.br/scielo.php?pid=S0100$15742001000300009 \&$ script=sci_abstract\&tlng =pt. Acesso em mar. de 2020.

FURLIN, Neiva; TAMANINI, Marlene. A diferença como política de resistência e de ressignificação da subjetividade feminina em campos de saberes masculinos. Revista Ciências Sociais, v.53, p.325-338, 2017.

GABRIELLI, Cassiana Panissa. Análise crítica do discurso e teoria feminista: diálogos frutíferos. Anais do Seminário Nacional Mulher e Literatura. Ilhéus: UESC, 2007.

HEERDT, B. Saberes Docentes: Gênero, Natureza da Ciência e Educação Científica.. 239 f. Tese (Doutorado em Ensino de Ciências e Educação Matemática) - Universidade Estadual de Londrina. Londrina. 2014.

HEERDT, B., Santos, A, P, O., OLIVEIRA, A, do C, B., FERREIRA, F, M., DOS ANJOS, M, C., Swiech, M, BANCKES, Tayná, Gênero no Ensino de Ciências publicações em periódicos no Brasil: o estado do conhecimento. ReBECEM, v. 2, n. 2, p. 217-241, 2018.

HARAWAY, Donna. Saberes Localizados: a questão da ciência para o feminismo e o privilégio da perspectiva parcial. Cadernos Pagu, v. 5: p. 07-41, 1995.

HARDING, Sandra. A instabilidade das categorias analíticas na teoria feminista. Revista Estudos Feministas. v. 1, n. 1, 1993.

KELLER, Evelyn. Fox. Qual foi o impacto do feminismo na ciência? Trad. Maria Luiza Lara. Cadernos Pagu, n. 27, p. 13-34, 2006.

LONGINO, Hellen. Feminist Epistemology as a Local Epistemology. Aristotelian Society Supplementary Volume, v. 71, n. 1, p. 19-35, 1997.

LONGINO, Hellen. E. Epistemologia feminista. In: SOSA, Ernesto (org.). Compêndio de Epistemologia - Grego. São Paulo: Loyola, 2008. p. 505-545. 
LOURO, Guacira. Lopes. Gênero, sexualidade e educação: uma perspectiva pós-estruturalista. 6. ed. Petropolis: Vozes, 2014.

LUKE, Carmen. Feminist pedagogy theory: Reflections on power and authority. Educacional Theory, v. 46, n. 3, 1996.

OLIVEIRA, Andréa, do C. B de. Ensino de evolução humana e as questões de gênero: percepção das (os) acadêmicas (os) de Ciências Biológicas. 130 f. Dissertação (Mestrado em Educação) - Universidade Estadual de Ponta Grossa, Ponta Grossa. 2019

ROHDEN, Fabíola. Uma ciência da diferença: sexo e gênero na medicina da mulher. 2a. ed. Rev. Rio de Janeiro: Editora Fiocruz, 2001.

SARDENBERG, Cecília, M. B. Relações de Gênero: uma breve introdução ao tema. Ensino e Gênero: Perspectivas. Salvador: UFBA/NEIM. p. 17-31, 2011.

SCHIEBINGER, Londa. O feminismo mudou a ciência? Trad. Raul Fiker. Bauru, São Paulo: EDUSC, 2001.

SCHWENGBER, Maria Simone V. O uso das imagens como recursos metodológicos. Org: MEYER, Dogmar E.; PARAísO, Marlucy A. In: Metodologias de pesquisas pós-Críticas em Educação. 2 Ed, Belo Horizonte: Mazza Edições, 2014.

SILVA, Ana Flávia. da; SANTOS, Ana. Paula. Oliveira dos; HEERDT, Bettina. Questões de Gênero na Educação Científica: tendências nas pesquisas nacionais e internacionais. In: Anais do Encontro Nacional de Pesquisa em Educação em Ciências, ENPEC 11, Florianópolis, 2017.

ZIHLMAN, Adrienne. The Paleoithic Glass Ceiling, In: HAGER, Lori D. Women in Human Evolution. Londres: Routledge, 1997. Disponível em:

https://people.ucsc.edu/ azihlman/publications/pdf/paleolithicglass.pdf. Acesso em: março de 2018. 